\title{
Combined effect of socioeconomic status, viral hepatitis, and lifestyles on hepatocelluar carcinoma risk in Korea
}

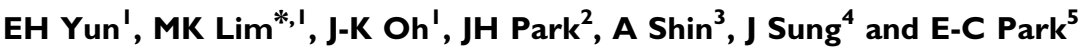 \\ 'Branch of Cancer Risk Appraisal \& Prevention, National Cancer Information Center, National Cancer Control Institute, National Cancer Center, \\ 323 Ilsan-ro, Ilsandong-gu, Goyangsi, Gyeonggi-do 410-769, Republic of Korea; ${ }^{2}$ Department of Social \& Preventive Medicine, School of Medicine, \\ Sungkyunkwan University, Suwon, Gyeonggi, Republic of Korea; ${ }^{3}$ Cancer Epidemiology Branch, Division of Cancer Epidemiology \& Management, Research \\ Institute, National Cancer Center, 323 Ilsan-ro, Ilsandong-gu, Goyangsi, Gyeonggi-do 4 I0-769, Republic of Korea; ${ }^{4}$ Department of Health Science and \\ Service, Graduate School of Public Health, Seoul National University, Seoul, Republic of Korea; ${ }^{5}$ National Cancer Control Institute, National Cancer Center, \\ 323 Ilsan-ro, Ilsandong-gu, Goyangsi, Gyeonggi-do 41 0-769, Republic of Korea
}

\begin{abstract}
BACKGROUND: The independent and combined effects of socioeconomic status (SES), viral hepatitis, and other lifestyle factors on hepatocellular carcinoma (HCC) risk have not been investigated among Koreans.

METHODS: From the National Cancer Center Hospital, 207 HCC cases and 828 age- and gender-matched controls aged 30 years or older were recruited. Socio-demographic and behavioural risk factors were ascertained through personal interview, and infection with hepatitis $B$ and $C$ viruses was determined by their serologic markers. Multivariate logistic regression and synergy index methods were applied for statistical analysis. RESULTS: HB surface antigen ( $\mathrm{HbsAg}$ ) and anti-HCV-positive rates were 149.3 and 185.1 times higher in cases than controls, respectively. Lifetime alcohol consumption (odds ratio: 2.96, 95\% Cl: 1.29-6.79), cigarette smoking (OR: 3.53, 95\% Cl: I.31-9.52), and family income (OR: 17.07, 95\% Cl: 4.27-68.25) were independently associated with the risk of HCC in subjects with or without viral hepatitis. Synergistic interaction on HCC risk was observed between low income and HBsAg positivity (SI: 3.12 , 95\% Cl: $1.5 \mathrm{I}-6.47$ ) and between low income and heavy alcohol intake (SI: 2.93, 95\% Cl: 1.24-6.89).

CONCLUSION: The inverse association with SES suggests SES as an independent and synergistic predictor of HCC. Heavy alcohol intake also showed a combined effect with low SES on HCC risk.

British Journal of Cancer (2010) 1 03, 74I-746. doi:I0.1038/sj.bjc.6605803 www.bjcancer.com

Published online 20 July 2010
\end{abstract}

(c) 2010 Cancer Research UK

Keywords: liver cancer; viral hepatitis; socioeconomic status; alcohol; BMI

Hepatocellular carcinoma (HCC, ICD-10 code: C22. 0) is one of the most common cancers worldwide, with high incidence in Asia and Africa and increasing rates in North America and Western Europe (Curado et al, 2007; Gomaa et al, 2008; World Health Organization, 2009). The hepatitis B virus (HBV) and hepatitis C virus (HCV) are its most important risk factors; causal links with dietary aflatoxin exposure and chronic alcohol consumption have also been established (Yu et al, 2000; Gomaa et al, 2008). Recently, smoking was classified as a group 1 carcinogen for HCC by the International Agency for Research on Cancer (IARC), and a significant inverse relationship with socioeconomic status (SES) has been reported (IARC Working Group on the Evaluation of Carcinogenic Risks to Humans, 2004; Joshi et al, 2008; Spadea et al, 2009). However, investigations of the independent and combined effects of these factors have been inconclusive, and lacking in HBV-endemic and HCC-prevalent areas.

Korea is an intermediate endemic area of HBV infection $(3.7 \%$ HB surface antigen (HBsAg)-positive rate), according to the Korea National Health and Nutrition Examination Survey conducted in 2007 (Ministry for Health, Welfare and Family Affairs, and Korea Centers for Diseases Control and Prevention, 2008). Hepatocellular

*Correspondence: Dr MK Lim; E-mail: mickey@ncc.re.kr Received 26 May 2010; revised 21 June 20I0; accepted 28 June 2010; published online 20 July 2010 carcinoma is also the predominant cancer with age-standardised incidence rates of 43.7 in men and 11.7 in women per 100000 (Shin et al, 2007), higher than in areas of North America, Africa, some parts of Asia, Europe, and Oceania (Curado et al, 2007). The independent and combined effects of HCC risk factors, including SES, have not been investigated.

We carried out a hospital-based, case-control study to (1) identify the independent risk for HCC associated with HBV and HCV infections, alcohol intake, cigarette smoking, and low SES and (2) measure the combined effects of these exposures after adjustment for other potential confounding variables.

\section{SUBJECTS AND METHODS}

Liver cancer patients were recruited from October 2002 to September 2006 based on information from the Order Communication System in the National Cancer Center Hospital (NCCH). A total of 207 HCC cases were enrolled in the study following medical chart examination to determine which cases met the inclusion criteria, such as newly diagnosed with HCC; having no history of cancer before visiting NCCH; without chronic diseases such as hypertension, diabetes mellitus, and liver disease, which may affect of HCC risk; age 30 years or older; complete serological profiles available for HBV and HCV; data available on alcohol intake, smoking, and family income; able to communicate with the 
interviewer; and who provided informed consent. The comparison group was recruited from health examinees visiting the same hospital for routine health check-ups, including cancer screenings, from May 2001 to May 2007 and identified as cancer free. Of 24889 health examinees, 12731 met the eligibility criteria applied to cases. Finally, 828 controls were selected through random frequency matching to provide four controls per case in the gender and age categories.

Individuals were interviewed by a trained interviewer using a structured questionnaire. The baseline surveys collected information on age (years 30-39, 40-49, 50-59,60-69, 70 and over), gender, marital status (married, single, including widowed and divorced), average family income ( $<$ US\$2000, 2000-4000, $\geqslant 4000$ per month), alcohol intake, cigarette smoking, and BMI $\left(\mathrm{kg} \mathrm{m}^{-2} ;<25,25-30, \geqslant 30\right)$.

The questionnaire on alcohol intake included drinking status (never, former, current); weekly number of drinks of the five most commonly consumed alcoholic beverages in Korea: soju (Korean compound liquor), beer, whisky, makkolli (Korean unstrained rice wine), and wine; age the subject started to drink alcohol; and duration of the habit. Taking into account different ethanol concentrations, alcohol consumption per volume for the five beverages was quantified by multiplying the absolute alcohol concentration by the volume of one drink for each type of beverage. Lifetime alcohol intake was divided into three groups $(<24 \mathrm{~g}$ per day, which included non-drinkers, $>24 \mathrm{~g}$ per day but $<48 \mathrm{~g}$ per day, and $>48 \mathrm{~g}$ per day) (National Institute on Alcohol Abuse and Alcoholism, 1992) for the analysis.

Cigarette smoking was classified as never, former, or current, with former and current smokers grouped together for the analysis. For former or current smokers, the average number of cigarettes smoked per day and duration of smoking was obtained. The former being classified as less than or more than 20 cigarettes per day.

Table I HCC cases and controls by selected characteristics with ORs and $95 \% \mathrm{Cls}$

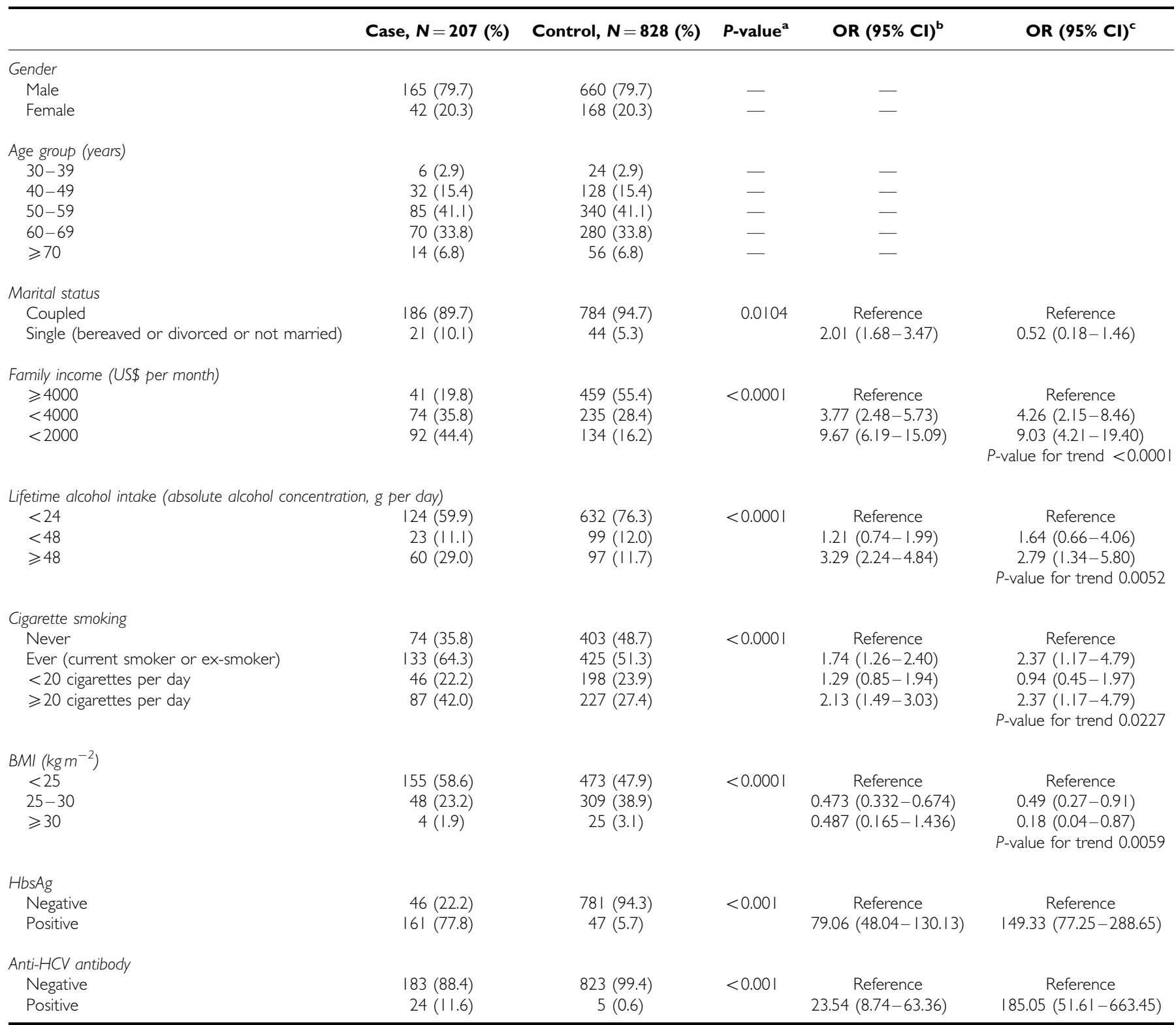

Abbreviations: $\mathrm{HbsAg}=$ serologic marker of hepatitis $\mathrm{B}$ virus surface antigen; anti-HCV antibody = serologic marker of hepatitis $\mathrm{C}$ virus antibody; $\mathrm{BMI}=$ body mass index $\mathrm{OR}=$ odds ratio; $95 \% \mathrm{Cl}=95 \%$ confidence interval. ${ }^{\mathrm{a}}$ Gender- and age-adjusted Cochran-Mantel-Haenszel $\chi^{2}$-test. ${ }^{\mathrm{b}}$ Multiple logistic regression analysis adjusted for gender and age. 'Multiple logistic regression analysis adjusted for gender, age, marital status, family income, lifetime alcohol intake, cigarette smoking, BMI, and positivity of HBsAg and anti-HCV as appropriate. 
Serum samples from all cases and controls were assayed for HBsAg and HCV antibody (anti-HCV) by enzyme-linked immunosorbent assays (HBsAg (V2) and HCV (V3), AxSYM System; Abott, Abbott Park, IL, USA).

\section{Statistical methods}

$\chi^{2}$-Tests were used to assess the significance of differences in the distributions of categorical variables between subjects in the case and control groups. Odds ratios (ORs) with corresponding $95 \%$ confidence intervals (95\% CIs) for the risk of HCC were estimated by stratified analysis and unconditional logistic regression modelling. The likelihood ratio test, which is the difference between the maximised log-likelihood statistics, was used to assess the significance of additional covariates in the model (Breslow and Day, 1980). All the analyses were carried out using the SAS statistical package (SAS Institute, Cary, NC, USA), and $P<0.05$ was considered statistically significant. The combined effects of risk factors were computed by applying the synergic index (SI) proposed by Rothman (1976).

The study was approved by the ethical committee of the National Cancer Center. Informed consent for interviews and for use of laboratory data was obtained from each subject.

\section{RESULTS}

Distribution of socio-demographic characteristics, alcohol consumption, cigarette smoking, BMI, and hepatitis virus infection is presented in Table 1 . There were more single individuals among the cases than the controls. Cases were in relatively lower income levels and were more likely to be heavy drinkers and to be smokers. Among cases, $77.8 \%$ were positive for HBsAg and $11.6 \%$ were positive for anti-HCV, whereas among controls, $5.7 \%$ were positive for $\mathrm{HBsAg}$ and $0.6 \%$ were positive for anti-HCV. Only one of the cases $(0.5 \%)$ and one of the controls $(0.1 \%)$ tested positive for both HBsAg and anti-HCV. HbsAg- and anti-HCV-positive rates were 149.3 and 185.1 times higher in cases than controls respectively. These differences were statistically significant after adjustment for the other covariates listed in Table 1. Increased risk of HCC was associated with low family income, heavy alcohol consumption, and heavy smoking, whereas higher BMI was associated with reduced risk of HCC. These differences in risk for HCC between the case and control groups were statistically significant (Table 1).

Odds ratios and CIs for the evaluation of interactions among selected HCC risk factors by HBsAg and anti-HCV status were also calculated. An inverse association was found with family income level among subjects with HBsAg and/or anti-HCV (OR for $<$ US $\$ 4000 v s \geqslant 4000: 5.38,95 \%$ CI: $2.14-13.53$; OR for < US $\$ 2000$ $v s \geqslant 4000: 5.17,95 \%$ CI: $1.89-14.16)$ and with neither HBsAg nor anti-HCV (OR for <US\$4000 vs $\geqslant 4000$ : 14.93, 95\% CI: $1.77-$ 125.84, OR for <US $\$ 2000 v s \geqslant 4000: 61.71,95 \%$ CI: $7.43-513.81$ ), even if it was around 12 times higher among subjects with neither HBsAg nor anti-HCV than among subjects with HBsAg and/or anti-HCV. Higher lifetime alcohol intake was also associated with increased risk of HCC among subjects with HBsAg and/or antiHCV (OR: 3.03, 95\% CI: 1.13-8.18) and among subjects with neither HBsAg nor anti-HCV (OR: 4.01, 95\% CI: 1.22-13.22), although significantly increased ORs were found only among heavy drinkers ( $\geqslant 48 \mathrm{~g}$ per day) in both groups. Smoking more than 20 cigarettes per day increased the risk of HCC among subjects with HBsAg and/or anti-HCV (OR: 4.11, 95\% CI: 1.44-11.70), whereas having a BMI $>25 \mathrm{~kg} \mathrm{~m}^{-2}$ decreased HCC risk among subjects with neither HBsAg nor anti-HCV (OR: $0.16,95 \%$ CI: $0.03-0.73$ ) only. These linear trends for increasing risk of HCC were significant in

Table 2 OR and 95\% Cl for the association of HCC with selected risks by HBsAg and/or anti-HCV status

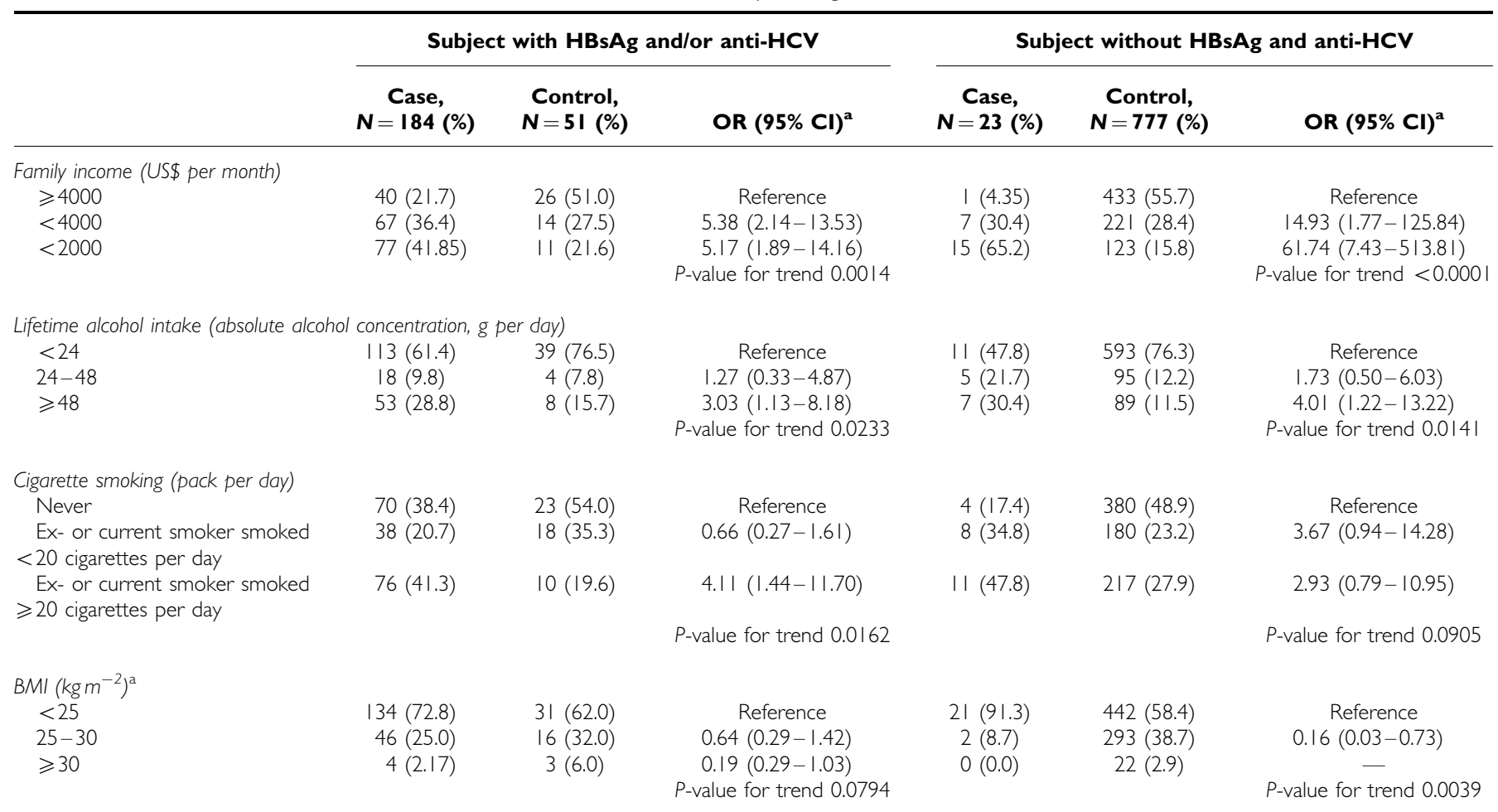

Abbreviations: $\mathrm{HBsAg}=$ serologic marker of hepatitis $\mathrm{B}$ virus surface antigen; anti-HCV antibody = serologic marker of hepatitis $\mathrm{C}$ virus antibody; $\mathrm{BMI}=$ body mass index; $\mathrm{OR}=$ odds ratio; $95 \% \mathrm{Cl}=95 \%$ confidence interval. ${ }^{2}$ Multiple logistic regression analysis adjusted for gender, age, marital status, family income, lifetime alcohol intake, cigarette smoking, and BMI as appropriate. 
both age- and gender-adjusted models and in all covariate-adjusted models (Table 2).

Table 3 presents the independent and combined effects of HBV and other selected risk factors. Definite independent risk of both HBsAg positivity (OR: 158.66, 95\% CI: 83.00-303.30) and antiHCV positivity (OR: 255.71, 95\% CI: $64.71-999.99$ ) were identified when the effects of other potential risk factors were considered. However, no combined effect of HBsAg and anti-HCV positivity was found (SI: 0.04, 95\% CI: $0.00-1.02$ ). Independent and combined effects of HBsAg and other selected risk factors were also identified. Lifetime alcohol consumption (OR: 2.96, 95\% CI: 1.29-6.79), cigarette smoking (OR: 3.53 , 95\% CI: $1.31-9.52$ ), and family income (OR: 17.07, 95\% CI: 4.27-68.25) were independently associated after controlling for the effects of HBsAg positivity and after adjustment for other covariates, although the independent risk of HBsAg positivity was much higher in each comparison. The combined effect of low family income and HBsAg positivity was more than additive and was statistically significant (SI: 3.12, 95\% CI: $1.51-6.47)$. The combined effect of lifetime alcohol intake and cigarette smoking with $\mathrm{HBsAg}$ positivity was marginal (SI: 2.36; 95\% CI: 0.99-5.65) and was not statistically significant (Table 3).

No independent or combined effects of potential risk factors associated with anti-HCV positivity were found to be statistically significant due to the small number of anti-HCV-positive subjects in both the case and control groups (data not shown).

Table 4 presents the pairwise interaction of family income, lifetime alcohol intake, and cigarette smoking on risk of HCC. An independent risk of family income for lifetime alcohol intake (OR: 4.55, 95\% CI: 2.20-9.39) and cigarette smoking (OR: 2.56, $95 \%$ CI: $1.04-6.32$ ) was found. Heavy drinkers ( $\geqslant 24 \mathrm{~g}$ per day) with lower income ( $<$ US $\$ 4000$ per month) were at very high risk for HCC relative to non-drinkers or moderate drinkers who reported family income $>$ US $\$ 4000$ per month. The combined effect was more than the sum of the two individual effects (SI: 2.93, 95\% CI: 1.24-6.89). Independent risk of cigarette smoking for alcohol intake and of alcohol intake for cigarette smoking was also found, although in combination they were not statistically significant.

\section{DISCUSSION}

There is more than one risk factor for HCC, and risk estimation is not simply additive; it can increase dramatically when two risk factors are present concomitantly. These attributes make simple risk estimation and establishment of strategic plans for HCC prevention and clinical intervention difficult. Therefore, some studies have addressed the independent and combined effects of viral infection and other potential risk factors, including alcohol consumption and smoking behaviour (Kuper et al, 2000; Mori et al, 2000; Jee et al, 2004; Yuan et al, 2004; Ribes et al, 2008). However, for HCC-prevalent areas, studies on the independent and combined effect of these risk factors are lacking.

An important finding is the combined effect of HCC risk with low family income, heavy alcohol intake, and HBV infection, in addition to a significant inverse association with low family income that have risk factors for HCC. Few studies have investigated SES in addition to other exposures to measure the independent and combined effects on risk of HCC (Joshi et al, 2008; Spadea et al, 2009). A direct association between cancer and SES could not be established and there is lack of studies of the relative or attributable risk of SES adjusting for demographic and behavioural factors ( $\mathrm{Yu}$ et al, 2000; Ji and Hemminki, 2005; Gwenn et al, 2007). Our findings suggest a definite independent and combined effect of low SES on risk of HCC when using family income as a direct indicator of SES in a multivariate model

Table 3 Interaction of HBsAg and anti-HCV positivity, alcohol intake, cigarette smoking, and family income on HCC risk

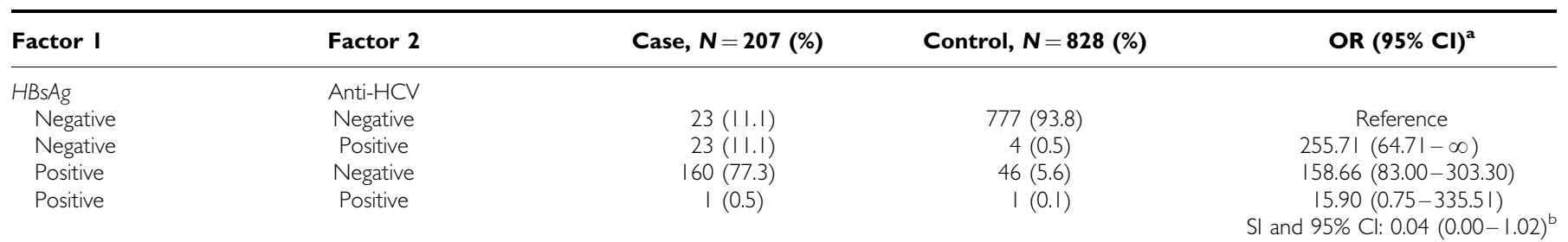

$\begin{array}{ccc}\text { HBsAg } & \text { Lifetime alcohol intake } & \\ & \text { (Absolute alcohol concentration, g per day) } & \\ \text { Negative } & <24 & 25(12.1) \\ \text { Negative } & \geqslant 24 & 21(10.1) \\ \text { Positive } & <24 & 99(47.8) \\ \text { Positive } & \geqslant 24 & 62(30.0)\end{array}$

$\begin{array}{cc}\text { HBsAg } & \text { Cigarette smoking } \\ \text { Negative } & \text { Never } \\ \text { Negative } & \text { Ever } \\ \text { Positive } & \text { Never } \\ \text { Positive } & \text { Ever }\end{array}$

$\begin{array}{ccc}\mathrm{HBsAg} & \text { Family income (US\$ per month) } & \\ \text { Negative } & \geqslant 4000 & 4(1.9) \\ \text { Negative } & <4000 & 42(20.3) \\ \text { Positive } & \geqslant 4000 & 37(17.9) \\ \text { Positive } & <4000 & 124(59.9)\end{array}$

$\begin{array}{lrr}\text { HBsAg } & \text { Family income (US\$ per month) } & \\ \text { Negative } & \geqslant 4000 & 4(1.9) \\ \text { Negative } & <4000 & 42(20.3) \\ \text { Positive } & \geqslant 4000 & 37(17.9) \\ \text { Positive } & <4000 & 124(59.9)\end{array}$

$596(72.0)$

$185(22.3)$

$36(4.4)$

II (1.3)

SI and 95\% Cl: $2.36(0.99-5.65)^{\mathrm{b}}$
$13(6.3)$
$33(15.9)$
$61(29.5)$
$100(48.3)$

$\begin{aligned} & 382(46.1) \\ & 399(48.2) \\ & 21(2.5) \\ & 26(3.1) \\ & \text { SI and } 95 \% \mathrm{Cl}: 0.87(0.39-1.92)^{\mathrm{b}}\end{aligned}$

$436(52.7)$

$345(41.7)$

$23(2.8)$

$24(2.9)$

SI and 95\% Cl: $3.12(1.51-6.47)^{b}$
Reference

$2.96(1.29-6.79)$

$153.99(72.51-327.00)$

$367.11(135.48-994.74)$

Abbreviations: $\mathrm{Hbs} \mathrm{Ag}=$ serologic marker of hepatitis $\mathrm{B}$ virus surface antigen; anti- $\mathrm{HCV}$ antibody $=$ serologic marker of hepatitis $\mathrm{C}$ virus antibody: $\mathrm{OR}=0$ odds ratio; $95 \% \mathrm{Cl}=95 \%$ confidence interval. "Multiple logistic regression analysis adjusted for gender, age, marital status, family income, lifetime alcohol intake, cigarette smoking, BMI, and positivity of

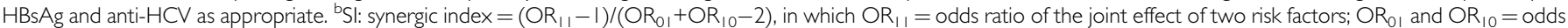
ratio of each risk factor in the absence of the other. 
Table 4 Pairwise interaction of family income, lifetime alcohol intake, and cigarette smoking on risk of HCC

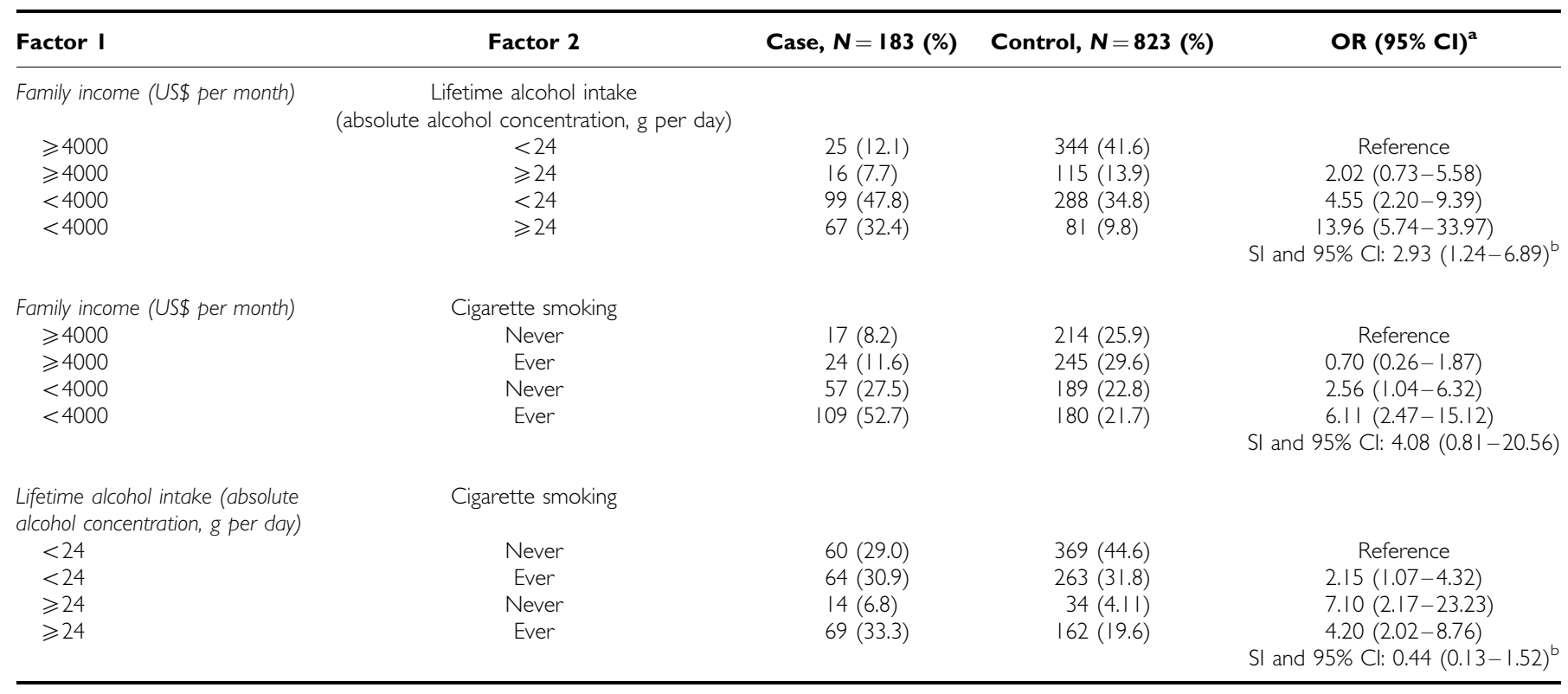

Abbreviations: $\mathrm{OR}=$ odds ratio; $95 \% \mathrm{Cl}=95 \%$ confidence interval. a Multiple logistic regression analysis adjusted for gender, age, marital status, family income, lifetime alcohol intake, cigarette smoking, BMI, and positivity of $\mathrm{HBsAg}$ and anti-HCV as appropriate. ${ }^{\mathrm{b}} \mathrm{Sl}$ : synergic index $=\left(O R_{11}-1\right) /\left(O R_{01}\right.$. $\left.+O R_{10}-2\right)$, in which $O R_{11}=0 d d s$ ratio of the joint effect of two risk factors; $O R_{01}$ and $O R_{10}=$ odds ratio of each risk factor in the absence of the other.

adjusted for other risk factors. In particular, the independent and combined effect of low SES was larger among subjects with neither HBsAg nor anti-HCV, which corresponds with IARC's summary of the differential presence, magnitude, and consistency of SES in mortality and incidence (Faggiano et al, 1997).

Recently, a definitive carcinogenic effect of alcohol consumption on HCC has been shown (Corrao et al, 2004; Tanaka et al, 2008), and some studies have suggested a significant combined effect (Kuper et al, 2000; Yuan et al, 2004; Marrero et al, 2005; IARC Working Group on the Evaluation of Carcinogenic Risks to Humans, 2007). However, the carcinogenic effects of alcohol are often underestimated, and there is a lack of research in East Asia, where alcohol consumption is increasing (Morgan et al, 2004; Boffetta and Hashibe, 2006). Our study results suggest an independent, rather than additive, combined risk for alcohol intake and HBsAg (OR: 2.36; 95\% CI: 0.99-5.65) in HBV-endemic and HCC-prevalent areas, although the association was not statistically significant. Furthermore, a significant combined effect for heavy alcohol consumption and low family income was also found.

A number of case-control and cohort studies have investigated smoking in relation to HCC risk and its interaction with risk for other diseases (Kuper et al, 2000; Mori et al, 2000; Jee et al, 2004; Yuan et al, 2004; Marrero et al, 2005), and a causal relationship between smoking and HCC has been established (IARC Working Group on the Evaluation of Carcinogenic Risks to Humans, 2004). However, studies are rare in HBV-endemic regions ( $\mathrm{Yu}$ et al, 2000), and our study suggests a relatively modest association between smoking and HCC, which could be caused by residual confounding from alcohol intake; we found no combined effect for cigarette smoking and other risk factors.

The present study suggests a significant, dose-response, preventive effect of higher BMI, although only among subjects with neither HBsAg nor anti-HCV, which is consistent with the World Cancer Research Fund and American Institute for Cancer Research (2007, p. 277) report. However, these results are not consistent with a meta-analysis of large-scale cohort studies, some of which have failed to show significant risk associated with BMI or have not considered other risk factors (Key et al, 2004;
Larsson and Wolk, 2007; Ohki et al, 2008; Renehen et al, 2008; Song et al, 2008). We were able to measure the relative contribution of obesity itself without confounding from chronic disease such as diabetes mellitus, hypertension, and liver cirrhosis, and other risk factors to be considered (Yuan et al, 2004). To clarify these inconsistencies, it is necessary to carry out further comprehensive prospective studies on the association between obesity and HCC.

To date, few studies have covered behavioural risk factors and SES in HCC irrespective of viral infection. There is also little evidence for interaction effect of these factors in viral infectionstatus subgroups, but the results of our study suggest independent risks associated with family income, lifetime alcohol intake, cigarette smoking, and BMI in such subgroups. These findings are relevant to prevention and intervention plans for HCC based on HBV and HCV prevalence in specific areas.

A recent meta-analysis of 32 studies and 1 study from Korea suggested independent and more than additive combined effects of viral infection in HCC causation (Sato et al, 1994; Donato et al, 1998; Montalto et al, 2002; Kirk et al, 2004). Our study findings also suggest that viral infection is a strong risk factor for HCC, with a larger independent effect for anti-HCV positivity than for HBsAg positivity. However, we observed no combined effect for concomitant infection with both types of viruses, which may be partly attributable to our small number of subjects co-infected with $\mathrm{HBV}$ and HCV, with low anti-HCV antibody rates (estimated around $1.3 \%$ ) in Korea (Shin, 2006).

This study has several limitations. Certain chronic diseases, such as diabetes mellitus and liver cirrhosis, that are suggested to influence HCC development (Jee et al, 2004; Yuan et al, 2004; Marrero et al, 2005; Boffetta and Hashibe, 2006; Park et al, 2006) unlikely affected our findings, as we excluded subjects with these diseases. Dietary and genetic susceptibility factors were not covered. Our control group was recruited through routine health check-ups, and as participation in such check-ups may reflect a concern for health or the practice of healthy habits, this may have biased the estimation of risk prevalence or HCC development. However, we did adjust for major lifestyle factors, such as alcohol, smoking, income, and BMI, in the analyses. Recall bias could also 
be an issue in this study, even though well-trained interviewers and comprehensive, structured questionnaires were used.

The findings of this study may further the understanding of HCC aetiology, with or without the presence of viral hepatitis.

\section{ACKNOWLEDGEMENTS}

This study was funded by the Korea National Cancer Center (Grant nos. NCC-0410140, NCC-0610550, and NCC-0710141).

\section{REFERENCES}

Boffetta P, Hashibe M (2006) Alcohol and cancer. Lancet Oncol 7: 149-156 Breslow NE, Day NE (1980) Statistical methods in cancer research. Vol. 1: the analysis of case-control studies. IARC Sci Pub. No.32. IARC: Lyon

Corrao G, Bagnardi V, Zambon A, La Vecchia C (2004) A meta-analysis of alcohol consumption and the risk of 15 diseases. Prev Med 38: 613-619

Curado MP, Edwards B, Shin HR, Storm H, Ferlay J, Heanue M, Boyle P (2007) Cancer Incidence in Five Continents, Vol. IX. IARC Scientific Publications No. 160. IARC: Lyon

Donato F, Boffeta P, Puoti M (1998) A meta-analysis of epidemiological studies on the combined effect of hepatitis $\mathrm{B}$ and $\mathrm{C}$ virus infections in causing hepatocellular carcinoma. Int J Cancer 75: 347-354

Faggiano F, Partanen T, Kogecinas M, Boffetta P (1997) Socioeconomic differences in cancer incidence and mortality. IARC Sci Pub 138: 65-176

Gomaa AI, Khan SA, Toledano MB, Waked I, Taylor-Robinson SD (2008) Hepatocellular carcinoma: epidemiology, risk factors and pathogenesis. World J Gastroenterol 14: 4300-4308

Gwenn M, Kunst AE, Stirbu I, Borrell C, Bopp M, Regidor E, Heine Strand B, Deboosere P, Lundberg O, Leclerc A, Costa G, Chastang JF, Esnaola S, Martikainen P, Mackenbach JP (2007) Socioeconomic inequalities in alcohol related cancer mortality among men; To what extent do they differ between Western European populations? Int J Cancer 121: 649-655

IARC Working Group on the Evaluation of Carcinogenic Risks to Humans (2004) IARC monographs on the evaluation of carcinogenic risks to humans. Vol. 83: Tobacco Smoke and Involuntary Smoking. IARC: Lyon

IARC Working Group on the Evaluation of Carcinogenic Risks to Humans (2007) IARC monographs on the evaluation of carcinogenic risks to humans. Vol. 96: Alcoholic Beverage Consumption. IARC: Lyon

Jee SH, Ohrr H, Sull JW, Samet JM (2004) Cigarette smoking, alcohol drinking, hepatitis B, and risk for hepatocellular carcinoma in Korea. J Natl Cancer Inst 96: 1851-1855

Ji J, Hemminki K (2005) Variation in the risk for liver and gallbladder cancers in socioeconomic and occupational groups in Sweden with etiological implications. Int Arch Occup Environ Health 78: 641 - 649

Joshi S, Song YM, Kim TH, Cho SI (2008) Socio-economic status and the risk of liver cancer mortality: a prospective study in Korean men. Public Health 122: $1144-1151$

Key TJ, Schatzkin A, Willett WC, Allen NE, Spencer EA, Travis RC (2004) Diet, nutrition, and prevention of cancer. Public Health Nutr 7: $187-200$

Kirk GD, Lesi OA, Mendy M, Akano AO, Sam O, Goedert JJ, Hainaut P, Hall AJ, Whittle H, Montesano R (2004) The Gambia liver cancer study: infection with hepatitis $\mathrm{B}$ and $\mathrm{C}$ and the risk of hepatocellular carcinoma in West Africa. Hepatology 39: 211-219

Kuper H, Tzonou A, Kaklamani E, Hsieh CC, Lagiou P, Adami HO, Trichopoulos D, Stuver SO (2000) Tobacco smoking, alcohol consumption and their interaction in the causation of hepatocellular carcinoma. Int J Cancer 85: 498 - 502

Larsson SC, Wolk A (2007) Overweight, obesity, and risk of liver cancer: a meta-analysis of cohort studies. Br J Cancer 97: 1005-1008

Marrero JA, Fontana RJ, Fu S, Conjeevaram HS, Su GL, Lok AS (2005) Alcohol, tobacco, and obesity are synergistic risk factors for hepatocelluar carcinoma. J Hepatol 42: 218-224

Ministry for Health, Welfare and Family Affairs, \& Korea Centers for Diseases Control and Prevention (KCDC) (2008) Korea National Health Examination Survey (NHANES) in 2007. KCDC: Seoul
Montalto G, Cervello M, Giannitrapani L, Dantona F, Terranova A, Castagnetta LA (2002) Epidemiology, risk factors, and natural history of hepatocellular carcinoma. Ann NY Acad Sci 963: 13-20

Morgan TR, Mandayam S, Jamal MM (2004) Alcohol and hepatocellular carcinoma. Gastroenterology 127: S87-S96

Mori M, Hara M, Wada I, Hara T, Yamamoto K, Honda M, Naramoto J (2000) Prospective study of hepatitis B and C viral infections, cigarette smoking, alcohol consumption, and other factors associated with hepatocellular carcinoma risk in Japan. Am J Epidemiol 151: 131-139

National Institute on Alcohol Abuse and Alcoholism (NIAAA) (1992) Alcohol Alert. No. 16: Moderate drinking. NIAAA: Washington, DC

Ohki T, Tateishi R, Sato T, Masuzaki R, Imamura J, Goto T, Yamashiki N, Yoshida H, Kanai F, Kato N, Shiina S, Yoshida H, Kawabe T, Omata M (2008) Obesity is an independent risk factor for hepatocellular carcinoma development in chronic hepatitis C patients. Clin Gastroenterol Hepatol 6: $459-464$

Park SM, Lim MK, Shin SA, Yun YH (2006) Impact of prediagnosis smoking, alcohol, obesity, and insulin resistance on survival in male cancer patients: National Health Insurance Corporation Study. J Clin Oncol 24: 5017-5024

Renehen AG, Tyson M, Egger M, Heller RF, Zwahlen M (2008) Body-mass index and incidence of cancer: a systematic review and meta-analysis of prospective observational studies. Lancet 371: 569-578

Ribes J, Clèries R, Esteban L, Moreno V, Bosch FX (2008) The influence of alcohol consumption and hepatitis $B$ and $C$ infections on the risk of liver cancer in Europe. J Hepatol 49: 233-242

Rothman KJ (1976) The estimation of synergy or antagonism. Am J Epidemiol 103: 506-511

Sato S, Fujiyama S, Tanaka M, Yamasaki K, Kuramoto I, Kawano S, Sato T, Mizuno K, Nonaka S (1994) Coinfection of hepatitis C virus in patients with chronic hepatitis B infection. J Hepatol 21: 159-166

Shin HR (2006) Epidemiology of hepatitis C virus in Korea. Intervirology 49: $18-22$

Shin HR, Jung KW, Won YJ, Kong HJ, Yim SH, Sung J, Seo SW, Kim KY, Lee SY, Kong IS, Hwang IK, Lee CW, Woo ZH, Lee TY, Choi JS, Yoo CI, Bae JM, Yoo KY (2007) National cancer incidence for the year 2002 in Korea. Cancer Res Treat 39: 139-149

Song YM, Sung J, Ha M (2008) Obesity and risk of cancer in postmenopausal Korean women. J Clin Oncol 26: 3395-3402

Spadea T, D'Errico A, Demaria M, Faggiano F, Pasian S, Zanetti R, Rosso S, Vicari P, Costa G (2009) Educational inequalities in cancer incidence in Turin, Italy. Eur J Cancer Prev 18: 169-178

Tanaka K, Tsuji I, Wakai K, Nagata C, Mizoue T, Inoue M, Tsugane S, Research Group for the Development and Evaluation of Cancer Prevention Strategies in Japan (2008) Alcohol drinking and liver cancer risk: an evaluation based on a systematic review of epidemiologic evidence among the Japanese population. Jpn J Clin Oncol 38: 816-838

World Cancer Research Fund, American Institute for Cancer Research (2007) Food, Nutrition, Physical Activity, and the Prevention of Cancer: A Global Perspective. p.277. AICR: Washington, DC

World Health Organization (2009) Mortality database. Accessed on 19 November 2009. Available from URL: http://www.who.int/whosis/en/

Yu MC, Yuan JM, Govindrajan S, Ross RK (2000) Epidemiology of hepatocellular carcinoma. Can J Gastroenterol 14: 703-709

Yuan JM, Govindarajan S, Arakawa A, Yu MC (2004) Synergism of alcohol, diabetes, and viral hepatitis on the risk of hepatocellular carcinoma in blacks and whites in the U.S. Cancer 101: 1009-1017 